\title{
STUDY OF RUNWAY DEVELOPMENT AT SUPADIO PONTIANAK INTERNATIONAL AIRPORT ON THE OPERATION OF A330-300 AIRCRAFT
}

\author{
Muhammad Wartino \\ Departemen Teknik Dirgantara \\ Sekolah Tinggi Teknologi Adisutjipto, Yogyakarta \\ Jalan Janti Blok R Lanud Adisutjipto, Yogyakarta \\ muhammad.wartino123@gmail.com,
}

\begin{abstract}
Modes of air transportation are also an option for making Hajj and Umrah trips in Indonesia. At this time the Supadio International Airport is extending the runway which was originally 2250 meters to 2600 meters. So, it is expected to be able to operate A330-300 aircraft for Hajj and Umrah flights. The method used in this research uses the calculation of ARFL (Aerodrome Reference Field Length), ACN-PCN (Aircraft Classification Number-Pavement Classification Number), runway width analysis and runway strips analysis From the results of research and analysis conducted with the runway extension of $2600 \mathrm{~m} \times 45 \mathrm{~m}$ with runway shoulders $2 m$ and PCN number 51/F/D/X/T A330-300 aircraft cannot operate at Supadio International Airport. So, that the runway development needs to be developed to $3097 \mathrm{~m} \times 45 \mathrm{~m}$ with runway shoulders 7,5m and PCN number of 89/F/D/X/T. So, that A330- 300 aircraft can operate for Hajj flights in Pontianak.
\end{abstract}

Keywords : Supadio international airport, A330-300 Aircraft, ARFL, ACN-PCN, Runway.

\section{Pendahuluan}

Indonesia merupakan negara kepulauan terbesar di dunia dengan jumlah lebih dari 17.000 pulau dan luas wilayah $1.904 .569 \mathrm{~km} 2$. Untuk menghubungkan seluruh daerah kepulauan ini dibutuhkan moda transportasi yang efektif, efisien dan mutakhir. Sehingga tidak heran jika transportasi udara menjadi pilihan bagi sebagian besar masyarakat di Indonesia yang mengutamakan efektifitas dalam beraktifitas [1][2]. Hal ini ditandai dengan perkembangan dunia penerbangan yang sangat pesat. Kondisi ini akan terus meningkat seiring dengan permintaan konsumen yang semakin kompleks. Alasan utama konsumen memilih angkutan udara adalah karena ketepatan waktu dan faktor keselamatan. laporan Universal Safety Oversight Audit Programme (USOAP) dari International Civil Aviation Organization (ICAO) dimana nilai implementasi dari keamanan dan keselamatan transportasi udara di Indonesia pada tahun 2017 mencapai 81.15\%. Jauh di atas rata-rata dunia yang yaitu 62\% [3][4][5]. Hasilnya, transportasi ini akan selalu dipilih oleh sebagian besar konsumen yang ingin melakukan perjalanan jauh untuk bekerja maupun berlibur. Hal ini juga berlaku untuk konsumen yang ingin melaksanakan ibadah haji dan umroh.

Berdasarkan UU Nomor 1 Tahun 2009 Tentang Penerbangan, definisi tentang Bandar Udara adalah kawasan di daratan dan/atau perairan dengan batas-batas tertentu yang digunakan sebagai tempat pesawat udara mendarat dan lepas landas, naik turun penumpang, bongkar muat barang, dan tempat perpindahan intra dan antarmoda transportasi, yang dilengkapi dengan 
fasilitas keselamatan dan keamanan penerbangan, serta fasilitas pokok dan fasilitas penunjang lainnya.

Jumlah Jemaah Haji asal Kalimantan Barat dalam lima tahun terakhir selalu meningkat. Besarnya antusias masyarakat Kalimantan Barat untuk melaksanakan ibadah haji dan umroh mendorong PT. Angkasapura II sebagai pengelola Bandar Udara Internasional Supadio Pontianak melakukan pengembangan bandara. Pengembangan bandara dilakukan dengan memperpanjang runway yang semula 2250 meter menjadi 2600 meter. Sehingga nantinya diharapkan dapat mengakomodir pesawat wide-body seperti Airbus A330-300 [6][7].

Di dalam penerbangan ada istilah Declared distances atau jarak-jarak operasional yang diberitahukan kepada penerbang untuk tujuan take-off, landing atau pembatalan take-off dengan aman. Jarak ini digunakan untuk menentukan apakah runway cukup untuk take-off atau landing seperti yang diinginkan atau untuk menentukan beban maksimum yang diijinkan untuk landing atau take-off. Di dalam KP 236 tahun 2019 Perhitungan declared distances harus dihitung sesuai dengan hal berikut:

a) Take-off run available (TORA) didefinisikan sebagai Panjang runway tersedia bagi pesawat udara untuk meluncur di permukaan pada saat take off. Pada umumnya ini adalah panjang keseluruhan dari runway; tidak termasuk stopway (SWY) atau clearway (CWY). TORA = Panjang Runway

b) Take-off distance available (TODA) didefinisikan sebagai jarak yang tersedia bagi pesawat udara untuk menyelesaikan ground run, lift-off dan initial climb hingga $35 \mathrm{ft}$. Pada umumnya ini adalah panjang keseluruhan runway ditambah panjang CWY. Jika tidak ada CWY yang ditentukan, bagian dari runway strip antara ujung runway dan ujung runway strip dimasukkan sebagai bagian dari TODA. Setiap TODA harus disertai dengan gradien take off bebas hambatan (obstacle clear take-off gradient) yang dinyatakan dalam persen.

\section{TODA $=$ TORA + CWY}

c) Accelerate-stop distance available (ASDA) didefinisikan sebagai panjang jarak meluncur take off yang tersedia (length of the take-off run available) ditambah panjang SWY. CWY tidak termasuk di dalamnya.

\section{ASDA = TORA + SWY}

Landing distance available (LDA) didefinisikan sebagai panjang dari runway yang tersedia untuk meluncur pada saat pendaratan pesawat udara. LDA dimulai dari runway threshold. Baik SWY maupun CWY tidak termasuk di dalamnya[[7][8][9][10]

\section{Metode Penelitian}

Dalam penelitian kali ini peneliti menggunakan metode penelitian evaluasi sumatif. Penelitian evaluasi merupakan kegiatan penelitian untuk mengumpulkan data, menyajikan informasi yang akurat dan obyektif. Sedangkan evaluasi sumatif adalah metode evaluasi yang lebih memberikan tekanan efektifitas pencapaian akhir dalam suatu penelitian. Tujuan dari evaluasi sumatif adalah untuk mengukur pencapaian program. Hal ini sejalan dengan tujuan penulis yang ingin menguji kelayakan pengembangan runway yang ada di Bandar Udara Internasional Supadio Pontianak dalam rencana pengperasian pesawat A330-300. 


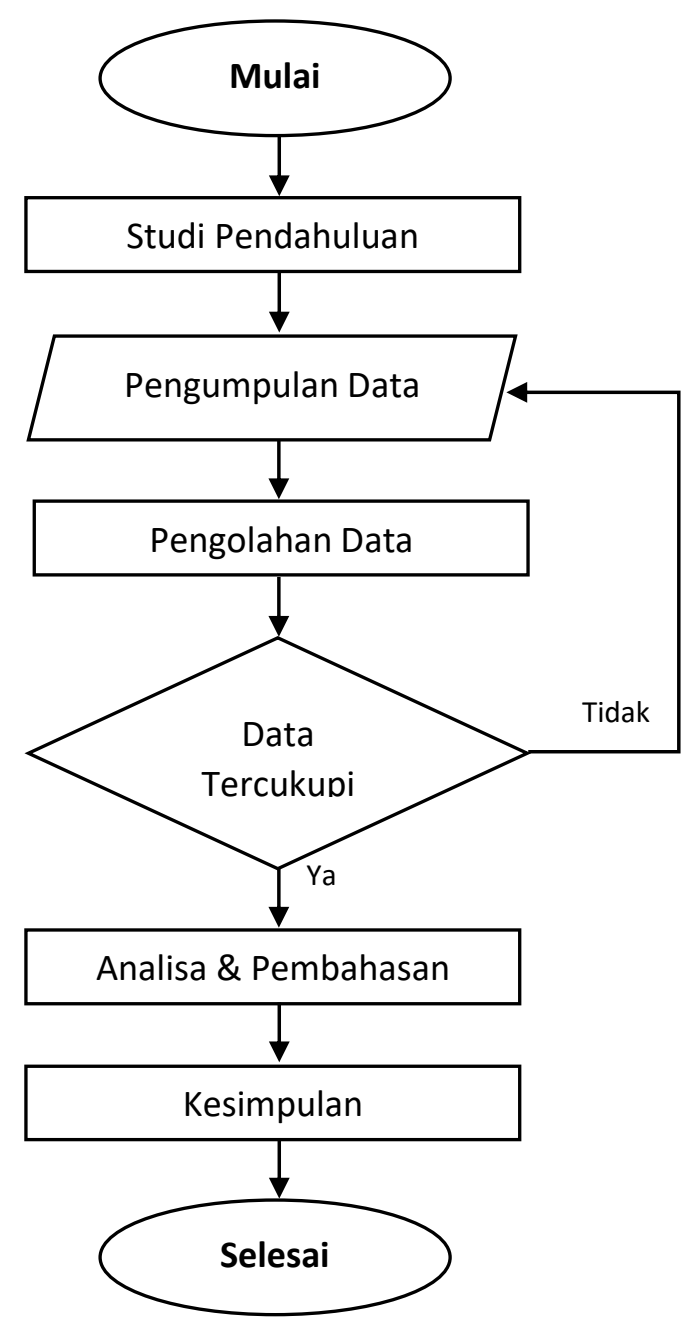

Gambar 3.1 Diagram Alir Penelitian

Dari gambar 3.1 dapat dijelaskan bahwa diagram alir dimulai dengan studi pendahuluan yang dilakukan oleh penulis, penulis melakukan studi pendahuluan dengan melakukan pencarian berita melalui media daring. Dengan melakukan studi pendahuluan penulis dapat merumuskan masalah dan tujuan penelitian yang dapat diambil dalam skripsi kali ini. Tahapan selanjutnya adalah pengumpulan data. Pengumpulan data yang dilakukan penulis dengan melakukan penelitian secara langsung di PT. Angkasa Pura II (Persero) kantor cabang Pontianak, dari penelitian kali ini didapatkan data primer yang digunakan penulis. Metode pengumpulan data yang dilakukan di tempat penelitian adalah dengan observasi secara langsung pada proyek pengembangan runway Bandar Udara Internasional Supadio Pontianak, wawancara dengan pihak yang terlibat baik secara langsung maupun tidak langsung, serta melakukan metode kepustakaan yang dilakukan penulis dengan membaca jurnal ilmiah yang dapat mendukung analisis dalam penulisan skripsi ini. Untuk mendapatkan data skunder peneliti mencari beberapa literasi baik dengan menggunakan buku maupun dengan memanfaatkan teknologi dengan mengakses beberapa situs di media daring yang dapat dipertanggung jawabkan sumbernya.

Setelah mendapatkan data yang dibutuhkan, penulis melakukan pengolahan data. Olah data dilakukan oleh penulis di tempat penelitian dengan didampingi oleh pembimbing sehingga data yang di dapatkan penulis adalah data yang bersifat umum dan dapat di pulikasikan. Setelah melakukan olah data, penulis akan kembali memastikan bahwa data yang dibutuhkan sudah tercukupi. Jika data belum tercukupi penulis akan kembali mencari data yang dibutuhkan 
sehingga data tercukupi. Data yang telah dirasa cukup akan dianalisa dan dilakukan pembahasan oleh penulis. Sehingga data yang dianalisis akan dapat ditarik kesimpulan dan dapat menyelesaikan masalah yang telah dirumuskan distudi pendahuluan.

Tahapan selanjutnya yang dilakukan penulis setelah melakukan Analisa dan pembahasan adalah dengan menarik kesimpuln terhadap data yang telah di Analisa pada tahapan sebelumnya sehingga dapat memberikan kesimpulan dan peyelesaian yang se-obyektif mungkin dalam peneitian kali ini.

\section{Hasil dan Pembahasan}

Dalam penelitiana kali penulis menganalisis panjang, lebar, serta kekuatan runway untuk pengoperasian pesawat A330-300.

\subsection{Panjang Runway}

Diketahui kondisi runway Bandar Udara Internasional Supadio yang direncanakan adalah sebagai berikut:

$\begin{array}{ll}\text { Panjang landasan rencana } & : 2.600 \mathrm{~m} \\ \text { ARFL } & : 2.790 \\ \text { Slope } & : 1 \% \\ \text { Elevasi runway } 33 & : 12 \mathrm{ft}=3,6576 \mathrm{~m} \\ \text { ART } & : 27,95^{\circ} \mathrm{C}\end{array}$

Untuk perhitungan Panjang runway harus dikoreksi terhadap elevasi, temperatur dan slope sebagai berikut:

Koreksi terhadap Elevasi:

$$
\begin{aligned}
L_{1} & =L_{0}+\left(L_{0} \times 0,07 \times \frac{H}{300}\right) \\
L_{1} & =2.790+\left(2.790 \times 0,07 \times \frac{3,6576}{300}\right) \\
& =2.792,381 \mathrm{~m}
\end{aligned}
$$

Koreksi terhadap Temperature:

$$
\begin{aligned}
L_{2} & =L_{1} \times(A R T-\text { Temperature standart }) \times 0,01+L_{1} \\
L_{2} & =2.792,381 \times(27,95-15) \times 0,01+2.792,381 \\
& =3.153,994 \mathrm{~m}
\end{aligned}
$$

Koreksi terhadap Slope :

$$
\begin{aligned}
L_{3} & =L_{2} \times S \times 0,1+L_{2} \\
L_{3} & =3.153,994 \times 1 \times 0,1+3.153,994 \\
& =3.469,393 \mathrm{~m} \approx 3470 \mathrm{~m}
\end{aligned}
$$

Dari perhitungan diatas dapat diketahui panjang landasan yang dibutuhkan untuk pengoperasian pesawat A330-300 dengan berat MTOW di Bandar Udara Internasional Supadio adalah 3.470 meter. Maka landasan pacu rencana yaitu $2600 \mathrm{~m}$, harus diperpanjang $870 \mathrm{~m}$.

\subsection{Lebar Runway}

Dalam menentukan lebar landasan ICAO memberikan persyaratan lebar runway sebagai berikut: 
Tabel 1. Lebar Landasan Pacu (Minimal)

\begin{tabular}{|c|c|c|c|c|c|c|}
\hline \multirow{2}{*}{ Code Number } & \multicolumn{6}{|c|}{ Code Letter } \\
\cline { 2 - 7 } & A & B & C & D & E & F \\
\hline $1^{\mathrm{a}}$ & $18 \mathrm{~m}$ & $18 \mathrm{~m}$ & $23 \mathrm{~m}$ & - & - & - \\
$2^{\mathrm{a}}$ & $23 \mathrm{~m}$ & $23 \mathrm{~m}$ & $30 \mathrm{~m}$ & - & - & - \\
3 & $30 \mathrm{~m}$ & $30 \mathrm{~m}$ & $30 \mathrm{~m}$ & $45 \mathrm{~m}$ & - & - \\
4 & - & - & $45 \mathrm{~m}$ & $45 \mathrm{~m}$ & $45 \mathrm{~m}$ & $60 \mathrm{~m}$ \\
a. The width of a precision approach runway should be not less than $30 \mathrm{~m}$ where the code number is 1 or 2. \\
\hline
\end{tabular}

Pesawat A330-300 memiliki Aerodrome Reference Code (ARC) 4E dengan kriteria wingspan 60,3 meter dan Outer Mean Gear Wheel Span (OMGSW) 12,6 meter. Sedangkan bandar udara Bandar Udara Internasional Supadio saat ini memiliki klasifikasi ARC 4C dengan lebar 45 meter dan bahu runway sebesar 1,5 meter di setiap sisinya. Untuk pengoperasian pesawat A330-300 klasifikasi runway di bandar udara ini harus ditingkatkan menjadi 4E. Dalam KP 326 tahun 2019 untuk kategori OMGSW 9 meter hingga kurang dari 15 meter harus memiliki lebar runway 45 meter. Kemudian untuk kategori bandara yang memiliki kode huruf $\mathrm{D}, \mathrm{E}$ dan $\mathrm{F}$ harus memiliki runway shoulders. Runway shoulders untuk pesawat dengan OMGSW 9 meter hingga kurang dari 15 meter, melebar secara simetris pada masing masing sisi runway sehingga lebar keseluruhan runway beserta shoulders-nya tidak kurang dari $60 \mathrm{~m}$ untuk code letter $\mathrm{D}$ dan $\mathrm{E}$.

Kemiringan melintang dibuat untuk mendukung pengaliran air. Agar ketika hujan turun air dapat mengalir dengan cepat. Dalam KP 326 tahun 2019 juga direkomendasikan kemiringan melintang untuk bandara dengan code letter E adalah 1,5\%. Untuk kemiringan bahu runway juga tidak boleh melebihi 2,5\%.

Dapat disimpulkan untuk mengoperasikan pesawat A330-300 Bandar Udara Internasional Supadio harus memperlebar runway shoulders-nya tidak kurang dari 6,5 meter pada setiap sisi runway. Dengan diperlebarnya runway shoulders di Bandar Udara Internasional Supadio klasifkasi Aerodrome Reference Code pada Bandar Udara Internasional Supadio akan meningkat dari 4C menjadi 4E.

\subsection{Kekuatan Runway}

Berdasarkan Aeronautical Information Publication Indonesia (VOL II) tanggal 05 Desember 2019. Bandar Udara Internasional Supadio memiliki nilai PCN 51/F/D/X/T yang berarti Kekuatan runway dipresentasikan dalam angka 51, dengan kategori flexible pavement permukaan asphalt. Subgrade strength category adalah ultra-low strength yang mewakili CBR $\leq 4$. Dengan kategori tekanan ban yang diijinkan adalah medium dengan batas tekanan 1,5 Mpa atau 218 Psi. Metode evaluasi bandar udara supadio adalah dengan menggunakan metode evaluasi analitis yaitu dengan pengujian secara khusus melalui teknologi (ilmu keteknikan).

Data Aircraft Classification Number pada Airbus Commercial Aircraft AC A330 dapat diketahui bahwa pesawat A330-300 dengan Maximum Ramp Weight (MRW) 242.900 kg memiliki nilai ACN untuk flexible pavement dengan subgrade ultra-low strength sebesar 103 dan 38 untuk Operating Empty Weight (OEW) 125.000 kg. Jadi untuk menghitung operating weight di Bandar Udara Internasional Supadio dengan nilai PCN 51/F/D/X/T untuk pesawat A330-300 dapat dihitung dengan menggunakan rumus sebagai berikut: Data Aircraft Classification Number pada Airbus Commercial Aircraft AC A330 dapat diketahui bahwa 
pesawat A330-300 dengan Maximum Ramp Weight (MRW) $242.900 \mathrm{~kg}$ memiliki nilai ACN untuk flexible pavement dengan subgrade ultra-low strength sebesar 103 dan 38 untuk Operating Empty Weight (OEW) $125.000 \mathrm{~kg}$. Jadi untuk menghitung operating weight di Bandar Udara Internasional Supadio dengan nilai PCN 51/F/D/X/T untuk pesawat A330-300 dapat dihitung dengan menggunakan rumus sebagai berikut:

$$
\begin{gathered}
A C N=A C N_{\text {Min }}+\left(A C N_{\text {Max }}-A C N_{\text {Min }}\right) \times\left(\frac{O W-O E W}{M R W-O E W}\right) \\
O W=O E W+(\ldots M R W-O E W) \times\left(\frac{P C N-A C N_{\text {Min }}}{A C N_{\text {Max }}-A C N_{\text {Min }}}\right)
\end{gathered}
$$

$\begin{array}{ll}\text { Jenis Pesawat } & : \text { A330-300 } \\ \text { MTOW } & : 242.000 \mathrm{~kg} \\ \text { MRW } & : 242.900 \mathrm{~kg} \\ \text { OEW } & : 125.000 \mathrm{~kg} \\ \text { ACN }_{\text {Max }} & : 103 \\ \text { ACN }_{\text {Min }} & : 38 \\ \text { PCN }_{\text {Bandara }} & : 51 / \mathrm{F} / \mathrm{D} / \mathrm{X} / \mathrm{T}\end{array}$

Dari data diatas nilai operating weight pesawat A330-300 yang dapat beroperasi di Bandar Udara Internasional Supadio adalah sebagai berikut:

$$
\begin{aligned}
O W & =125.000+(242.900-125.000) \times\left(\frac{51-38}{103-38}\right) \\
& =125.000+(117.900) \times\left(\frac{13}{65}\right) \\
& =125.000+23.580 \\
& =148.580 \mathrm{~kg}
\end{aligned}
$$

Jadi, untuk Bandar Udara Internasional Supadio dengan nilai PCN 51/F/D/X/T untuk pengoperasian pesawat A330 yang memiliki MTOW $242.900 \mathrm{~kg}$ runway hanya mampu menahan operasional Pesawat A330-300 dengan batasan Operating Weight sebesar $148.580 \mathrm{~kg}$.

Pesawat A330-300 milik maskapai Garuda Indonesia yang beroperasi di bandar udara internasional supadio Pontianak menuju bandar udara internasional king abdulaziz Jeddah dengan bandara alternatif Prince Mohammad Bin Abdulaziz International Airport Madinah mempunyai mempunyai data sebagai berikut:

Operating Weight $\quad: 216.763 \mathrm{~kg}$

Operating Empty Weight $\quad: 125.000 \mathrm{~kg}$

Maximum Ramp Weight $\quad: 242.900 \mathrm{~kg}$

$\mathrm{ACN}_{\text {Min }}: 38$

$\mathrm{ACN}_{\text {Max }}: 103$

Sehingga ACN dapat dihitung menggunakan persamaan 4:

$$
\begin{aligned}
A C N & =38+(103-38) \times\left(\frac{216.763-125.000}{242.900-125.000}\right) \\
& =88,590
\end{aligned}
$$

Jadi, pesawat A330-300 yang melakukan penerbangan dari Bandar Udara Internasional Supadio Pontianak (PNK) menuju King Abdulaziz International Airport Jeddah (JED) dengan 
alternatif Prince Mohammad Bin Abdulaziz International Airport Madinah (MED) dengan TOW $216.763 \mathrm{~kg}$ dapat beroperasi di runway pengembangan Bandar udara supadio, karena ARFL setelah dikoreksi terhadap elevasi, suhu dan slope adalah 2.475 meter sedangkan runway rencana adalah 2.600 meter. Serta PCN yang dibutuhkan dalam pengoperasian pesawat dengan Take-off weight tersebut adalah $89 / \mathrm{F} / \mathrm{D} / \mathrm{X} / \mathrm{T}$.

\section{Kesimpulan}

Hasil pengolahan data yang dilakukan, pesawat A330-300 untuk penerbangan haji tidak layak dioperasikan pada Bandar Udara Internasional Supadio Pontianak sehingga bandara harus meningkatkan spesifikasi menjadi; Panjang 3.470m; Lebar 60m; dan nilai PCN 89/F/D/X/T.

\section{Daftar Pustaka}

[1] Airbus S.A.S, 2005. Aircraft Characteristics Airport and Maintenance planning. Airbus S.A.S. Prancis.

[2] Direktorat Kelaikudaraan dan Pengoperasian Pesawat Udara. 2019. Civil Aircraft Registration 2019. Kementerian Perhubungan Republik Indonesia. Indonesia.

[3] Dondokambey, Felicia Geiby. Dkk. 2013. Perencanaan Pengembangan Bandar Udara (Studi Kasus: Bandar Udara Sepinggan Balikpapan). Universitas Sam Ratulangi. Manado.

[4] ICAO Doc 9157 AN/901. 2006. Aerodrome Design Manual Part 1 Runways. International Civil Aviation Organization.

[5] Pasaribu Hisar M., 2012. Sistem Transportasi Udara, Diktat Kuliah, Bandung: Departemen Teknik Penerbangan Institut Teknologi Bandung.

[6] Pemerintah Indonesia. 2009. Undang-Undang No. 1 Tahun 2009 Yang Mengatur Tentang Penerbangan. Lembaran Negara RI Tahun 2009, No. 25. Sekertariat Negara. Jakarta.

[7] Pemerintah Indonesia. 2019. Peraturan Direktur Jenderal Perhubungan Udara Aeronautical Information Publication (VOLL II). Sekertariat Negara. Jakarta.

[8] Pratama, Akhdi Martin. 2019. Runway Diperpanjang, Bandara Supadio Bisa Layani Penerbangan Haji dan Umroh. Jakarta: kompas.com.

[9] Warsito, Djoko. 2017. Manajemen Bandar Udara: Landasan Pacu, Taxiway, dan Apron. Erlangga. Jakarta.

[10] Werang, Basilius Redan. 2015. Pendekatan Kuantitatif dalam Penelitian Sosial. Calpulis. Yogyakarta. 